\title{
Comparison of keratometric measurements between color light-emitting diode topography and Scheimpflug camera
}

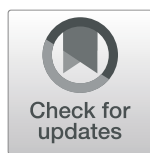

Xian-Hua Cui ${ }^{1,2}$, Young-Sik Yoo ${ }^{3}$, Youngju $\mathrm{An}^{4}$ and Choun-Ki Joo ${ }^{1 *}$ (D)

\begin{abstract}
Background: To determine the agreement of measurements between color light-emitting diode corneal topography (Cassini) and Scheimpflug camera keratometry (Pentacam HR).

Methods: The current retrospective study investigated 117 right eyes of 117 healthy patients before cataract surgery from June 2017 to July 2017. Steep K, flat K, mean K, astigmatism, and axis for both anterior and posterior corneal surface were measured using the two devices. The measured values were converted into $\mathrm{J}$ vectors such as $\mathrm{J} 0$ and J45. The mean difference for those measurement values were compared between the two instruments, and the agreement was evaluated using the Bland-Altman plot I.

Results: There were statistically significant differences in mean K (44.21D [43.34 to 45.34] and 44.30D [43.30 to 45.10] by Cassini and Pentacam $[P=0.004]$ ) and astigmatism (0.90D [0.58 to 1.30] and 0.70D [0.40 to 1.30] by Cassini and Pentacam $[P=0.002])$ on the anterior corneal surface and flat K $(-6.21 \mathrm{D}[-6.39$ to -6.07$]$ and $-6.30 \mathrm{D}$ [ -6.5 to -6.10$]$ by Cassini and Pentacam $[P<0.001])$, mean K $(-6.39 \mathrm{D}[-6.54$ to -6.25$]$ and $-6.40 \mathrm{D}[-6.60$ to -6.30$]$ by Cassini and Pentacam $[P=0.019]$ ), and astigmatism (0.33D [0.22 to 0.47$]$ and $0.30 \mathrm{D}$ [0.15 to 0.40$]$ by Cassini and Pentacam $[P=0.002])$ on the posterior corneal surface. The mean difference (= Cassini - Pentacam) with 95\% limit of agreement for mean $\mathrm{K}$ and astigmatism of the anterior corneal surface were $0.082 \mathrm{D}(-0.60$ to 0.76$)$ and $0.11 \mathrm{D}(-0.73$ to 0.95$)$ for measurements obtained by the two instruments, respectively. Regarding keratometric values from the posterior corneal surface, the mean differences for flat $\mathrm{K}$, mean $\mathrm{K}$, and astigmatism were $-0.081 \mathrm{D}(-0.42$ to 0.26$),-0.030 \mathrm{D}(-0.32$ to 0.26$)$, and $0.067 \mathrm{D}$ ( -0.33 to 0.46$)$, respectively. Intraclass correlation coefficients for steep K, flat K, mean $\mathrm{K}$, and vector J0 were higher than 0.9 in the anterior cornea. Positive correlation in steep K, flat K, mean K, astigmatism, and J0 was found between two devices in both anterior and posterior cornea $(P<0.001)$.
\end{abstract}

Conclusions: Corneal refractive power and astigmatism tend to be higher when measured using Cassini than Pentacam HR in both anterior and posterior cornea. The two different devices might not be used interchangeably.

Trial registration: Retrospectively registered. Registration number: KC17RESI0439.

Keywords: Astigmatism, Cornea, Ocular refraction

\footnotetext{
* Correspondence: ckjoo@catholic.ac.kr

'Department of Ophthalmology and Visual Science, College of Medicine,

Seoul St. Mary's Hospital, The Catholic University of Korea, 222 Banpo-daero,

Seocho-gu, Seoul 06591, South Korea

Full list of author information is available at the end of the article
}

(c) The Author(s). 2019 Open Access This article is distributed under the terms of the Creative Commons Attribution 4.0 International License (http://creativecommons.org/licenses/by/4.0/), which permits unrestricted use, distribution, and reproduction in any medium, provided you give appropriate credit to the original author(s) and the source, provide a link to the Creative Commons license, and indicate if changes were made. The Creative Commons Public Domain Dedication waiver (http://creativecommons.org/publicdomain/zero/1.0/) applies to the data made available in this article, unless otherwise stated. 


\section{Background}

In cataract surgery, refractive power of the cornea plays an important role in the calculation of power in artificial intraocular lens (IOL) insertion. Accurate measurement of the corneal refractive power and astigmatism are crucial factors in intraoperative correction of astigmatism as well as for improvement of the patient's vision and satisfaction with treatment $[1,2]$. Both the magnitude and axis of the anterior and posterior cornea determine the overall corneal astigmatism [3].

Among devices used for anterior segment biometry, Pentacam HR (software version 6.07r12, Oculus, Wetzlar, Germany), a type of rotational Scheimpflug camera, and the recently developed Cassini (software version 2.4.0, i-optics, The Hague, Netherlands) [4] which uses the color-LED method, can measure the curvature of not only the anterior but also the posterior cornea. Recently, studies that emphasize the importance of posterior corneal astigmatism in cataract surgery for the minimization of postoperative remnant astigmatism have increased [5-7]. The clinical applicability of these devices is increasing the accuracy for the actual corneal astigmatism measurement using the posterior corneal astigmatism, especially in toric IOL implantation $[3,8]$. Pentacam HR analyzes the tomographic images obtained from a single rotating camera, whereas Cassini is a new topographer that uses a multicolor (red, yellow, and green) spot pattern, which analyses the specular reflection using 679 Light-emitting diode (LED) spots superimposed on the cornea. Pentacam HR corrects errors caused by eye movements and plentiful data are present in the literature regarding the good or excellent repeatability and reproducibility of data measured using Pentacam HR. However, there are some reports that Pentacam HR has low repeatability due to eye movement because of its long measurement time [9], whereas Cassini reconstructs the specular reflections from 679 color-LEDs by a point-to-point method, thereby instantly analyzing the shapes of the anterior and posterior cornea [5].

This study aims to comparatively analyze the refractive power, astigmatism, and axis of the anterior and posterior cornea and assess whether the two devices can be used interchangeably.

\section{Methods}

A retrospective study was conducted on 117 eyes of 117 patients undergoing normal cataract surgery in our center's Ophthalmology Department from June 7, 2017 to July 27, 2017. The stage of cataract for them ranged from 1 to 4 by Pentacam nucleus staging system. Right eye was selected from each subject. The study was conducted in adherence to the Declaration of Helsinki as well as under the approval of the Medical Research Ethics Board of the Catholic University of Korea (IRB approval number: KC17RESI0439). Eyes with preoperative pathologies that could affect corneal astigmatism, such as pterygium, severe corneal turbidity, corneal pathology due to severe dry eye, and diseases of the eyelid, orbit, and conjunctiva were excluded from the analysis.

Two investigators measured the curvature of the anterior and posterior cornea, as well as astigmatism, prior to surgery using color light-emitting diode corneal topography (Cassini; i-Optics, Hague, Netherlands) and Scheimpflug camera keratometry (Pentacam HR; Oculus, Wetzlar, Germany) in that order, at an interval of under $10 \mathrm{~min}$. Keratometry of their eyes was performed before applying any kind of eye drops. We performed the procedure after guiding the subject to fix their chin and forehead on the equipment's test bed and to observe the internal fixation target in the test equipment while sitting in front of the test equipment. In order to minimize errors in measurement due to changes in the tear layer, patients were encouraged to blink sufficiently before each measurement. The same investigator took three measurements, and the average of the three values was used in subsequent analyses to compare each test result. Both Cassini and Pentacam HR provided qualitative information, and only those with "OK" or "measurement successful" results were included in the analysis.

Cassini reconstructs the specular reflections from 679 color-LEDs by a point-to-point method, thereby instantly analyzing and measuring the shapes of the anterior and posterior cornea, the corneal curvature, lower-order aberration, and higher-order aberration $[3,10]$. The Pentacam HR hardware comprises a single rotating camera. It obtains tomographic images of the anterior segment by means of 2-s scans through a $450-\mathrm{nm}$ blue light-emitting diode using the same principles as that of a $360^{\circ}$ rotating Scheimpflug camera [11]. However, keratometry using the Scheimpflug method has a relatively long measurement time and is sensitive to eye movement.

Cassini and Pentacam HR were both used to measure the steep $\mathrm{K}$, flat $\mathrm{K}$, mean $\mathrm{K}$, astigmatism, and axis of the anterior and posterior sides of a central 3-mm corneal area (simulated keratometry). J0 and J45, which are Jackson cross-cylinder (JCC) values, were used for the analysis of astigmatism through power vector analysis [12]. The magnitude and axis were measured three times and expressed as J0 and J45, respectively. The average values for both J0 and J 45 were calculated and then converted back to magnitude and axis. The formula to obtain the Jackson cross-cylinder is as follows:

$$
\begin{aligned}
& \mathrm{J} 0=-\mathrm{C} / 2 \times \cos 2 \theta \\
& \mathrm{J} 45=-\mathrm{C} / 2 \times \sin 2 \theta \\
& (\mathrm{C} ; \text { negative astigmatism }=\text { flat } \mathrm{K} \text {-steep } \mathrm{K} ; \theta=\text { flat meridian })
\end{aligned}
$$

SPSS software (ver. 18.0; SPSS Inc., Chicago, IL) and R software (ver. 3.5.2; R foundation for Statistical Computing, 
Table 1 Overview of astigmatism magnitude

\begin{tabular}{llll}
\hline Device & Anterior Surface & Posterior Surface & Total Cornea \\
& Median [IQR] (Range) (D) & Median [IQR] (Range) (D) & Median [IQR] (Range) (D) \\
\hline Cassini & $0.90[0.58-1.30](0.09-3.32)$ & $0.33[0.22-0.47](0.04-0.89)$ & $0.72[0.40-1.20](0.04-3.02)$ \\
Pentacam HR & $0.70[0.40-1.30](0.10-3.50)$ & $0.30[0.15-0.40](0.00-0.80)$ & $0.60[0.34-1.18](0.10-3.20)$ \\
\hline
\end{tabular}

$D$ diopters, IQR interquartile range, $N$ number of cases

Vienna, Austria) were used for statistical analyses. The paired $\mathrm{t}$-test was used to compare the average measured values between the two devices. Intraclass correlation coefficient (ICC) was calculated to evaluate the degree of agreement between the two devices. Pearson correlation was used to obtain the correlation coefficient between the measurement methods and the scatter plots were produced using the LOWESS curve. The agreement between the values measured using the two devices was analyzed by the Bland-Altman plot and is expressed as $95 \%$ limits of agreement. $P$ values of less than 0.05 were deemed statistically significant.

\section{Results}

Mean patient age was $65.1 \pm 11.5$ years (range 22-93). Thirty-four subjects (29\%) were men, and 57 eyes (49\%) were right eyes. The median astigmatism values for both anterior, posterior, and total cornea were larger in Cassini than in Pentacam HR (Table 1).

The difference (= Cassini - Pentacam HR) in average values of the anterior cornea was $0.08 \mathrm{D}(-1.30$ to 1.50 , $P=0.057$ ) for steep $\mathrm{K}, 0.01 \mathrm{D}$ ( -1.10 to $0.80, P=0.692$ ) for flat $\mathrm{K}, 0.08 \mathrm{D}(-0.89$ to $1.02, P=0.011)$ for mean $\mathrm{K}$, $3.88^{\circ}$ ( -174.9 to $\left.174.3, P=0.485\right)$ for axis, $-0.04 \mathrm{D}(-0.74$ to $0.53, P=0.045)$ for vector J0, $0.00 \mathrm{D}$ ( -0.56 to 0.53 , $P=0.845)$ for 545 , and $0.11 \mathrm{D}(-1.41$ to $1.44, P=$ 0.004 ) for astigmatism (Table 2). In the anterior cornea, the mean $\mathrm{K}$, vector $\mathrm{J} 0$, and astigmatism showed statistically significant differences. The difference in average values measured using the two devices in the posterior cornea was $0.00 \mathrm{D}$ ( -0.42 to $0.40, P=0.791$ ) for steep $\mathrm{K}, 0.08 \mathrm{D}(-0.41$ to $0.51, P=0.000)$ for flat $\mathrm{K}, 0.03 \mathrm{D}(-0.45$ to $0.37, P=0.033)$ for mean $\mathrm{K}, 4.25^{\circ}$ ( -17.2 to $\left.177.4^{\circ}, P=0.639\right)$ for axis, $-0.04 \mathrm{D}(-0.35$ to $0.24, P=0.002)$ for vector J0, $-0.01 \mathrm{D}$ ( -0.39 to $0.36, P=0.493)$ for $\mathrm{J45}$, and $0.07 \mathrm{D}(-0.41$ to $0.76, P$ $=0.001)$ for astigmatism. In the posterior cornea, flat $\mathrm{K}$, mean $\mathrm{K}$, vector $\mathrm{J} 0$, and astigmatism showed statistically significant differences.

ICC between the two devices were higher than 0.9 for steep $\mathrm{K}$, flat $\mathrm{K}$, mean $\mathrm{K}$, and vector J0 in the anterior cornea and lower than 0.75 for astigmatism, axis, vector J0, and vector J45 in the posterior cornea. Pearson correlation showed significantly positive correlation in steep $\mathrm{K}$, flat $\mathrm{K}$, mean $\mathrm{K}$, astigmatism, and vector J0 between the two devices: in the anterior cornea, $\mathrm{r}=0.950, \mathrm{r}=0.962, \mathrm{r}=0.967, \mathrm{r}=0.796, \mathrm{r}=0.897$, respectively $(P<0.001$, Fig. 1$)$; in the posterior cornea, $\mathrm{r}=0.780, \mathrm{r}=0.753, \mathrm{r}=0.806, \mathrm{r}=0.392, \mathrm{r}=0.448$, respectively $(P<0.001$, Fig. 2$)$. In the anterior cornea, J45 showed a significant positive correlation between the two devices $(r=0.757, P<0.001)$; however, in the posterior cornea, J45 showed no significant correlation $(\mathrm{r}=0.176, P=0.058$, Figs. 1 and 2$)$.

The range of $95 \%$ limits of agreement in the anterior cornea was -0.80 to $0.96 \mathrm{D}$ for steep $\mathrm{K},-0.71$ to $0.74 \mathrm{D}$ for flat $\mathrm{K},-0.60$ to $0.76 \mathrm{D}$ for mean $\mathrm{K},-0.72$ to $0.95 \mathrm{D}$ for astigmatism, -0.51 to $0.42 \mathrm{D}$ for $\mathrm{J} 0$, and -0.39 to $0.40 \mathrm{D}$ for $\mathrm{J} 45$ (Fig. 3); and in the posterior cornea, -0.34 to $0.35 \mathrm{D}$ for steep $\mathrm{K},-0.26$ to $0.42 \mathrm{D}$ for flat $\mathrm{K},-0.26$ to $0.32 \mathrm{D}$ for mean $\mathrm{K},-0.33$ to $0.46 \mathrm{D}$ for astigmatism, 0.29 to $0.22 \mathrm{D}$ for J0, and -0.24 to $0.22 \mathrm{D}$ for $\mathrm{J} 45$ (Fig. 4).

Table 2 Comparison of corneal refractive power $(K)$ measured by Cassini and Pentacam HR

\begin{tabular}{|c|c|c|c|c|c|c|c|c|}
\hline & \multicolumn{4}{|c|}{ Anterior corneal surface } & \multicolumn{4}{|c|}{ Posterior corneal surface } \\
\hline & Cassini & Pentacam HR & $P$-value* & ICC & Cassini & Pentacam HR & $P$-value* & ICC \\
\hline Steep K & $44.80(41.60-48.80)$ & $44.72(41.30-48.40)$ & 0.057 & 0.974 & $6.58(5.97-7.13)$ & $6.58(5.80-7.20)$ & 0.791 & 0.876 \\
\hline Flat K & $43.82(41.22-47.07)$ & $43.81(41.10-46.80)$ & 0.692 & 0.981 & $6.23(5.64-6.90)$ & $6.31(5.60-6.90)$ & $0.000^{* *}$ & 0.859 \\
\hline Mean K & $44.34(41.46-47.84)$ & $44.25(41.20-47.40)$ & $0.011^{* *}$ & 0.983 & $6.4(5.83-6.95)$ & $6.43(5.70-7.00)$ & $0.033^{* *}$ & 0.892 \\
\hline Astigmatism & $1.03(0.09-3.32)$ & $0.91(0.10-3.50)$ & $0.004^{* *}$ & 0.886 & $0.35(0.04-0.89)$ & $0.29(0.00-0.80)$ & $0.001^{* *}$ & 0.563 \\
\hline Axis & $91.67(0.00-179.00)$ & $87.78(1.10-178.10)$ & 0.485 & 0.763 & 93.80(0.00-180.00) & 89.55(0.20-179.70) & 0.639 & -0.422 \\
\hline J0 & $-0.02(-1.33-1.36)$ & $0.03(-0.84-1.67)$ & $0.045^{* *}$ & 0.945 & $0.09(-0.28-0.39)$ & $0.13(-0.12-0.40)$ & $0.002^{* *}$ & 0.591 \\
\hline$J 45$ & $0.01(-0.96-0.98)$ & $0.00(-0.79-0.52)$ & 0.845 & 0.851 & $-0.01(-0.36-0.42)$ & $0.00(-0.13-0.25)$ & 0.493 & 0.252 \\
\hline
\end{tabular}

Values are presented as Mean (Range) (D)

ICC intra-class correlation coefficient

*Paired t-test 

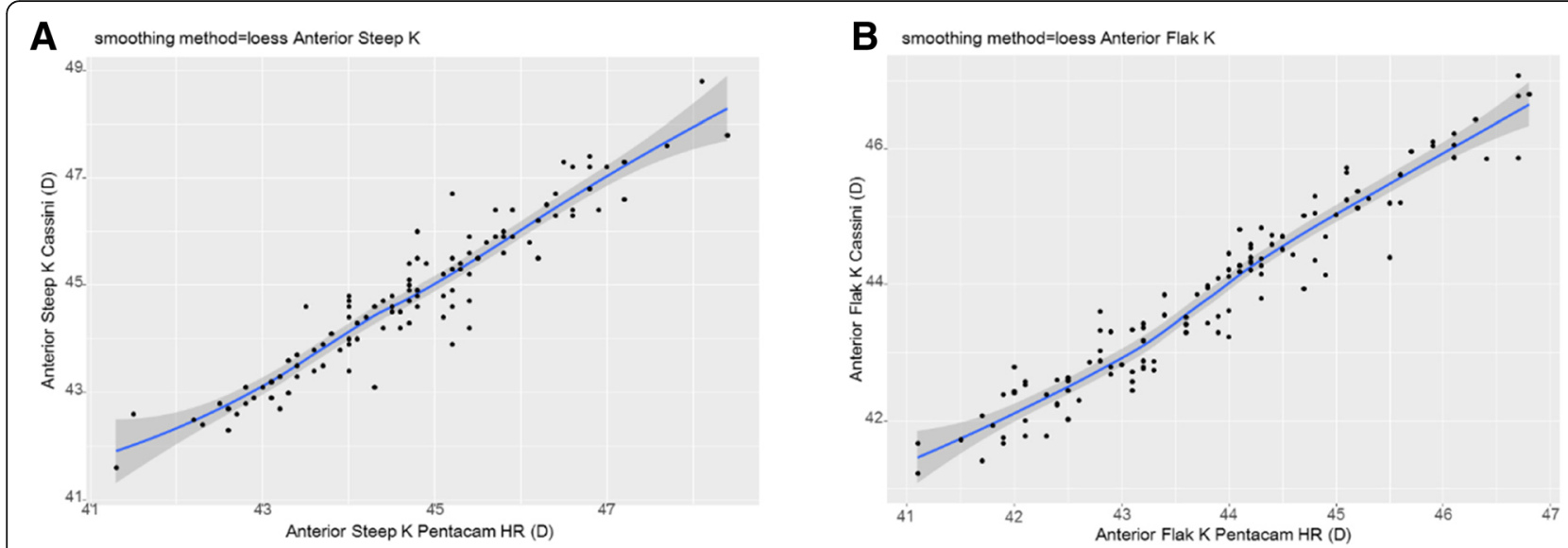

C smoothing method=loess Anterior Mean $\mathrm{K}$

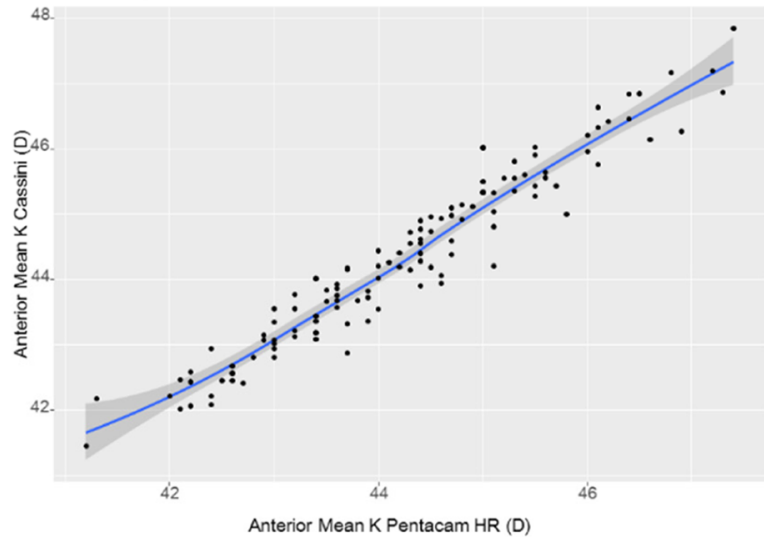

E

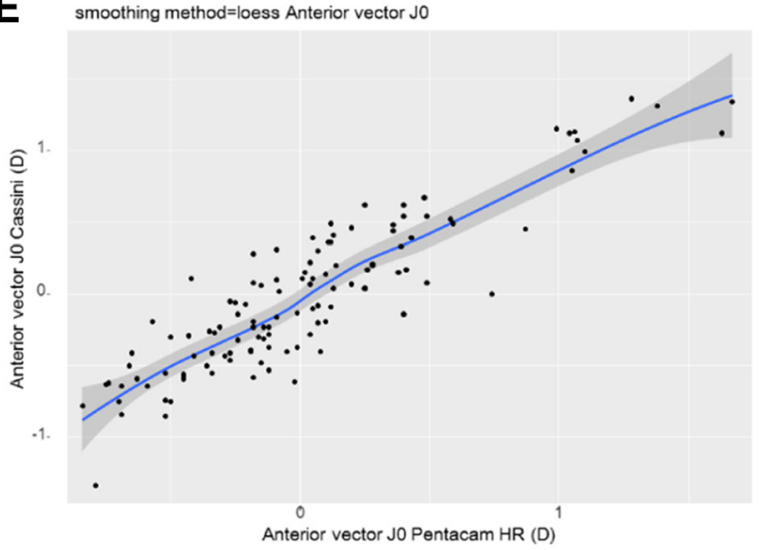

F smoothing method=loess Anterior vector J45

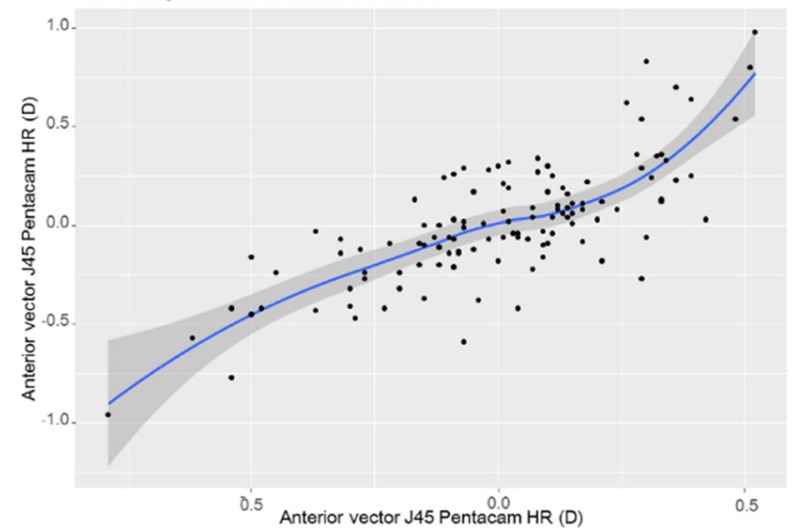

Fig. 1 Pearson correlation of anterior segment parameters between Cassini and Pentacam HR. a Anterior Steep K, b Anterior Flat K, c Anterior Mean K, d Anterior Astigmatism, e Anterior vector J0, f Anterior vector J45. K=Keratometric diopter

The amount of anticipated residual refractive astigmatism and axis did not differ between the two groups (Table 3). As a result, it is predicted that astigmatism of the toric IOL will not be affected by the two devices.

\section{Discussion}

The observed corneal refractive power and astigmatism tended to be higher when using Cassini than when using Pentacam in the anterior and posterior cornea in the present study. The $95 \%$ limit of agreement was quite 


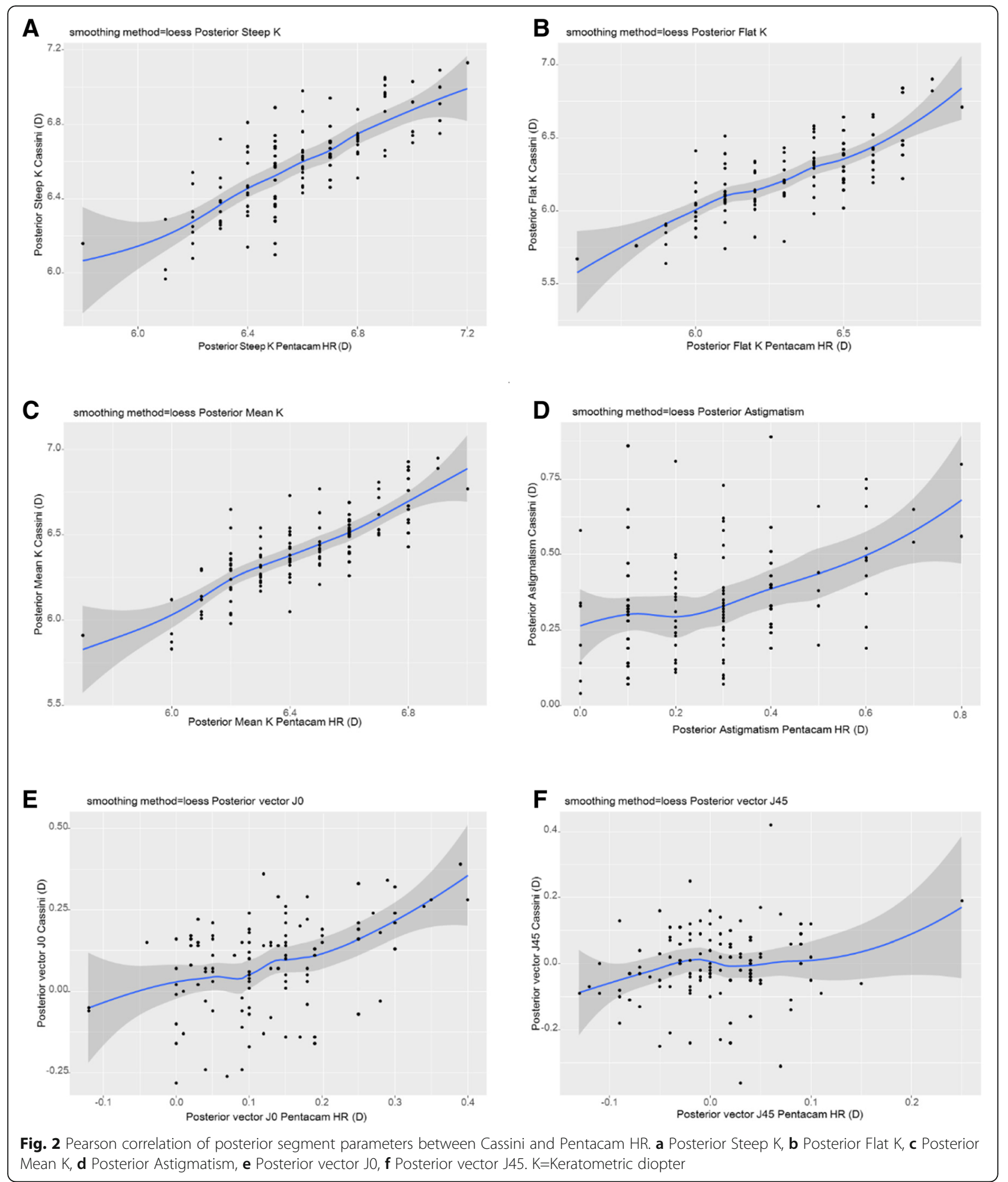

large for most variables measured, especially for the anterior corneal surface, comfortably extending beyond 0.5 $\mathrm{D}$ except for J0 and J45. The results for the posterior surface shared similar characteristics. This shows that the agreement was low from a clinical point of view.
Studies have reported that ignoring the posterior corneal values may result in erroneous measurement of overall astigmatism $[5,13]$. In WTR astigmatism, ignoring the posterior astigmatism may cause overcorrection. In younger patients, in particular, slight WTR astigmatism 

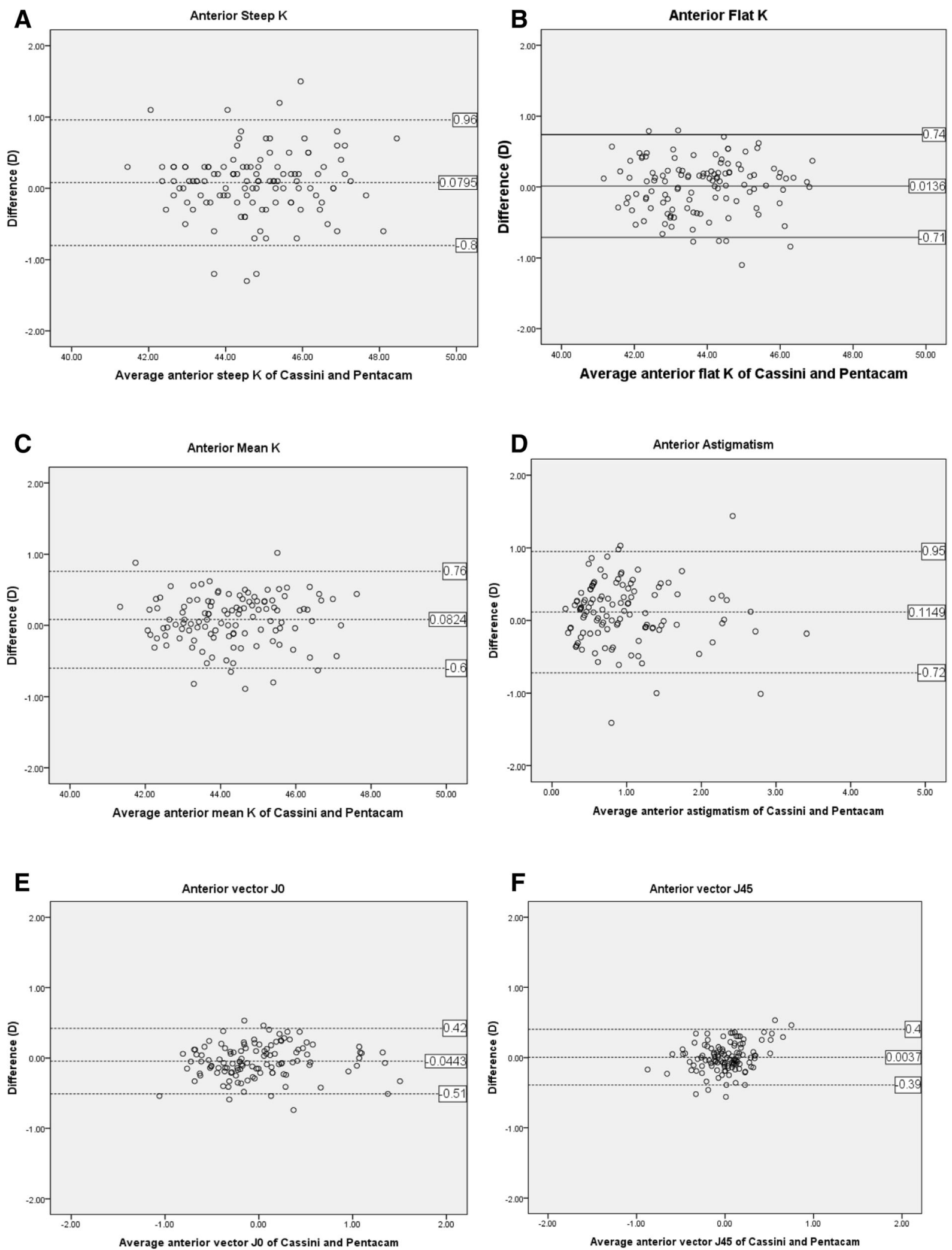

Fig. 3 Bland-Altman plots of anterior segment parameters using Cassini and Pentacam HR. a Anterior Steep K, b Anterior Flat K, c Anterior Mean K, d Anterior Astigmatism, e Anterior vector J0, $\mathbf{f}$ Anterior vector J45. K=Keratometric diopter 

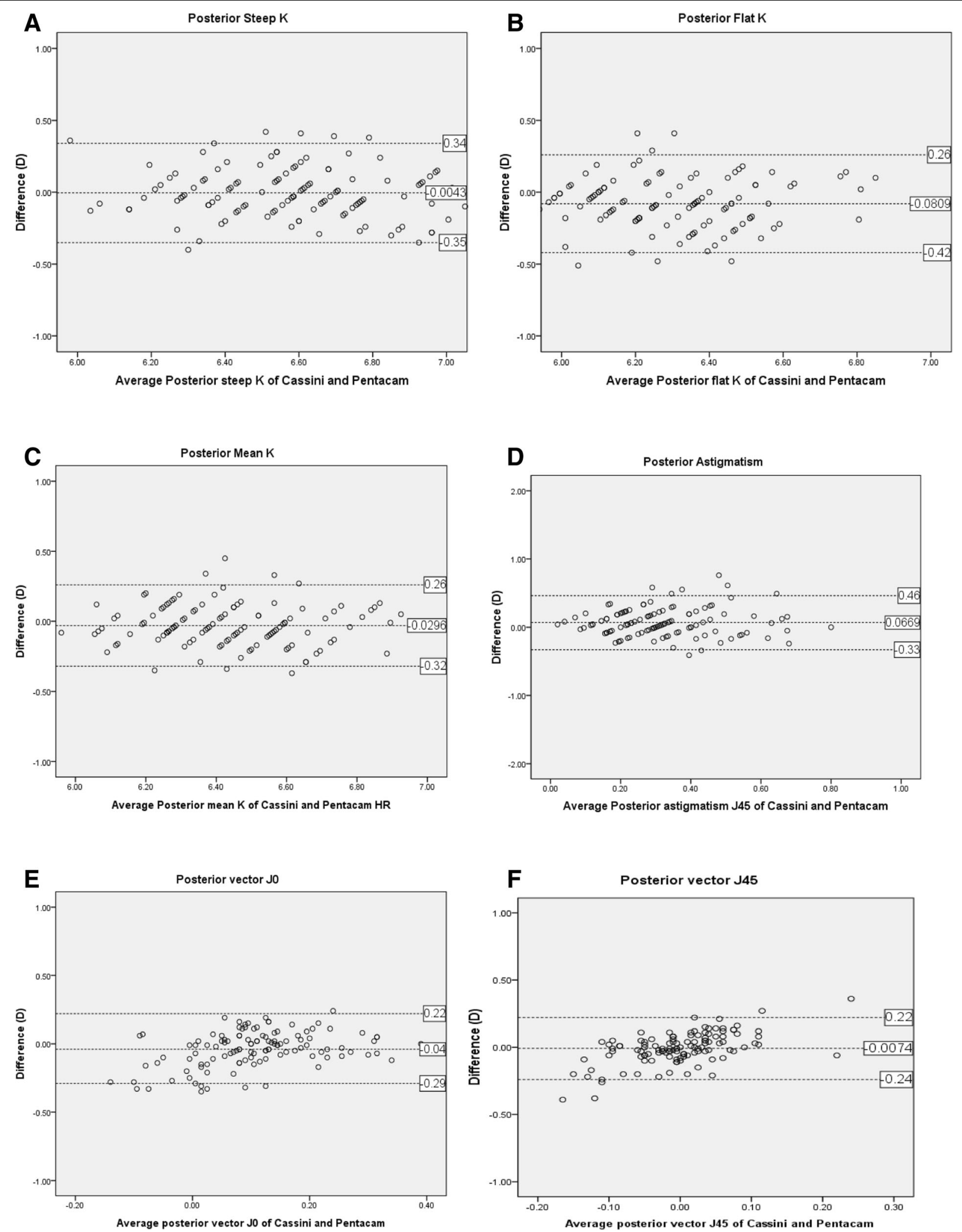

Fig. 4 Bland-Altman plots of posterior segment parameters using Cassini and Pentacam HR. a Anterior Steep K, b Anterior Flat K, c Anterior Mean K, d Anterior Astigmatism, e Anterior vector J0, f Anterior vector J45. K=Keratometric diopter 
Table 3 Anticipated residual refractive astigmatism calculated by Alcon online toric intraocular lens calculator using keratometric values from Cassini and Pentacam HR

\begin{tabular}{llll}
\hline & Cassini & Pentacam HR & $P$-value* \\
\hline Magnitude & $0.91 \pm 0.57$ & $0.93 \pm 0.66$ & 0.965 \\
Meridian & $99 \pm 69$ & $85 \pm 74$ & 0.487 \\
\hline
\end{tabular}

Values are presented as Mean \pm SD

*Paired t-test

must remain after correction, considering the tendency to progress to ATR astigmatism with age. Therefore, when inserting an IOL for the correction of astigmatism, care must be taken to consider posterior astigmatism and avoid overcorrection [14-16]. Additionally, one of the main limitations of Scheimpflug imaging is the low resolution and poor quality of anterior segment scans. In this regard, Cassini is known to produce better images with higher definition and to enable accurate measurement of the posterior cornea using multiple LED points. Although some researchers have evaluated its agreement with Pentacam $\mathrm{HR}$, they focused on the measurement accuracy of total corneal astigmatism in toric IOL implantation or evaluated the agreement level in the relatively small sample size $[3,17]$. The present study comparatively analyzed not only total corneal astigmatism but also refractive power, astigmatism, and the difference in astigmatic axes of the anterior and posterior cornea, and assessed whether the two devices can be used in a complementary manner.

Comparison of measurements using Cassini and Pentacam HR indicated significant differences in the average refractive power of the cornea and astigmatism in both the anterior and the posterior cornea. Pentacam HR reconstructs the images of the anterior segment into a 3-dimensional structure and allows for the visualization of the anterior and posterior cornea, as well as measurement of astigmatism in certain areas of the cornea. In a study on 493 eyes, Ho et al. [8] reported that corneal astigmatism measured by Pentacam HR showed a difference of $0.24 \pm 0.16 \mathrm{D}$ in size and $7.4 \pm 10.3^{\circ}$ in axis compared to anterior astigmatism, possibly due to the presence of posterior corneal astigmatism. Klijn et al. [18] compared the refractive power of the cornea measured with Cassini, Keratron, Lenstar, and Pentacam HR and reported values of $43.42 \pm 1.37 \mathrm{D}$ and $43.44 \pm 1.46 \mathrm{D}$ using the Cassini and Pentacam HR, respectively, without significant difference $(P=0.64)$. In the present study, the average values measured in the anterior cornea by the Cassini and Pentacam HR was $44.34 \pm 1.35 \mathrm{D}$ and $44.25 \pm 1.34 \mathrm{D}$, respectively and in the posterior cornea was $6.43 \pm 0.23 \mathrm{D}$ and $6.43 \pm 0.24 \mathrm{D}$ for mean $\mathrm{K}$. The average corneal curvature and the average astigmatism size measured by the two devices showed small differences of maximum $0.43 \mathrm{D}$ and $0.54 \mathrm{D}$ in the anterior cornea and maximum $0.18 \mathrm{D}$ and $0.27 \mathrm{D}$ in the posterior cornea.
The two devices may not be used interchangeably. In the present study, the results of Pearson correlation analysis showed high correlation between the corneal refractive powers of the anterior and posterior cornea $(\mathrm{r}=$ 0.950 and $r=0.806$, respectively); however, based on the $95 \%$ agreement limit of $-0.60 \sim 0.76 \mathrm{D}$ and $-0.26 \sim 0.32 \mathrm{D}$ in the anterior and posterior cornea, respectively. This might be caused that the two devices have different methods of measuring the corneal curvature and the accuracy of measurement or the calibration of each device affects the values. Though both devices measure the same 3-mm central corneal area, Pentacam HR requires a longer duration of time compared with Cassini; therefore, factors involved in patient cooperation, such as eye stability, compensatory saccadic movement, and consistent eye opening, would affect the test results.

The limitation of this study is that measurement error may have occurred, since two investigators were involved in the measurement and in addition, inter-reader agreement could not be determined. Moreover, the study was conducted only on normal corneas, and difference due to the innate characteristics of each device was not considered. In the present retrospective study, we calculated the required sample size using $G$ Power for a power of 0.8. The number of required samples was 128 . However, the number of samples was as low as 117 people. Additional studies that compensate for the above limitation and those with repeated measurements are required for results that are more accurate.

\section{Conclusions}

In conclusion, both two devices are useful in measuring keratometry, but the two devices might be noninterchangeable.

\section{Abbreviations}

ATR: Against-the-rule; DV: Difference Vector; ICC: Intraclass correlation coefficient; IOL: Intraocular Lens; IQR: Interquartile range; JCC: Jackson crosscylinder; LED: Light-emitting diode; TCP: Total corneal power; WTR: Withinthe-rule

\section{Acknowledgements}

None applicable.

\section{Funding}

This work was supported by Basic Science Research Program through the National Research Foundation of Korea (NRF) funded by the Ministry of Education (2016R1A6A1A03010528).

\section{Availability of data and materials}

The datasets obtained and/or analyzed during the current study are available from the corresponding author on reasonable request.

\section{Authors' contributions}

XHC, YSY, YA and CKJ had the idea of the comparison keratometric measurements between Color Light-Emitting Diode topography and Scheimpflug camera and the analysis of refractive power, astigmatism, and axis of the anterior and posterior cornea to evaluate whether the two devices can be used interchangeably. XHC programmed and drafted the initial manuscript. YSY, YA and CKJ designed the data files, writing, and reviewing the manuscript. CKJ was 
also a major contributor in writing and reviewing the manuscript. All authors read and approved the final manuscript.

\section{Ethics approval and consent to participate}

The study was conducted in adherence to the Declaration of Helsinki as well as under the approval of the Institutional Review Board of Seoul St. Mary's Hospital (IRB \#KC17RESI0439). The informed consent was waived in this retrospective study.

\section{Consent for publication}

Not applicable.

\section{Competing interests}

The authors declare that they have no competing interests.

\section{Publisher's Note}

Springer Nature remains neutral with regard to jurisdictional claims in published maps and institutional affiliations.

\section{Author details}

'Department of Ophthalmology and Visual Science, College of Medicine, Seoul St. Mary's Hospital, The Catholic University of Korea, 222 Banpo-daero, Seocho-gu, Seoul 06591, South Korea. ${ }^{2}$ Department of Ophthalmology, Yanbian University Hospital, \#1327 Juzi St, Yanji 133000, Jilin Province, People's Republic of China. ${ }^{3}$ Department of Ophthalmology, Samsung Medical Center, Sungkyunkwan University School of Medicine, 81 Ilwon-ro, Gangnam-gu, Seoul 06351, South Korea. ${ }^{4}$ Department of Optometry, Baekseok Culture University, 58, Munam-ro, Dongnam-gu, Cheonan-si, Chungcheongnam-do, South Korea.

\section{Received: 12 October 2018 Accepted: 12 April 2019}

Published online: 26 April 2019

\section{References}

1. Olsen T. Sources of error in intraocular lens power calculation. J Cataract Refract Surg. 1992;18:125-9.

2. Norrby S. Sources of error in intraocular lens power calculation. J Cataract Refract Surg. 2008;34:368-76.

3. Klijn S, Reus NJ, van der Sommen CM, Sicam VA. Accuracy of Total corneal astigmatism measurements with a Scheimpflug imager and a color lightemitting diode corneal topographer. Am J Ophthalmol. 2016;167:72-8.

4. Kanellopoulos AJ, Asimellis G. Forme Fruste keratoconus imaging and validation via novel multi-spot reflection topography. Case Rep Ophthalmol. 2013:4:199-209.

5. Koch DD, Ali SF, Weikert MP, Shirayama M, Jenkins R, Wang L. Contribution of posterior corneal astigmatism to total corneal astigmatism. J Cataract Refract Surg. 2012;38:2080-7.

6. Reitblat O, Levy A, Kleinmann G, Abulafia A, Assia El. Effect of posterior corneal astigmatism on power calculation and alignment of toric intraocular lenses: comparison of methodologies. J Cataract Refract Surg. 2016;42:217-25.

7. Cheng LS, Tsai CY, Tsai RJ, Liou SW, Ho JD. Estimation accuracy of surgically induced astigmatism on the cornea when neglecting the posterior corneal surface measurement. Acta Ophthalmol. 2011;89:417-22.

8. Ho JD, Tsai CY, Liou SW. Accuracy of corneal astigmatism estimation by neglecting the posterior corneal surface measurement. Am J Ophthalmol. 2009;147:788-95, 795.e1-2.

9. Braaf B, Dubbelman M, van der Heijde RG, Sicam VA. Performance in specular reflection and slit-imaging corneal topography. Optom Vis Sci. 2009;86:467-75.

10. Weikert MP, Koch DD, Wang D. Evaluation of corneal topography based on color LED technology. San Francisco, California, USA: Paper presented at the American Society of Cataract and Refractive Surgery Symposium and Congress; 2013.

11. Lim TH, Lee JR, Choi KY, Cho BJ. Anterior and posterior corneal spherical aberration measured with Pentacam in the Korean. J Korean Ophthalmol Soc. 2010:51:816-21.

12. Thibos LN, Wheeler W, Horner D. Power vectors: an application of Fourier analysis to the description and statistical analysis of refractive error. Optom Vis Sci. 1997;74:367-75

13. Tejedor J, Guirao A. Agreement between refractive and corneal astigmatism in pseudophakic eyes. Cornea. 2013;32:783-90.
14. Bauer NJ, de Vries NE, Webers CA, Hendrikse F, Nuijts RM. Astigmatism management in cataract surgery with the AcrySof toric intraocular lens. J Cataract Refract Surg. 2008;34:1483-8.

15. Kim CS, Ryu JW, Kim HS, Lee YC. Distribution and change of total astigmatism, corneal astigmatism and residual astigmatism with age in patient with emmetropia. J Korean Ophthalmol Soc. 2005;46:485-93.

16. Ho JD, Liou SW, Tsai RJ, Tsai CY. Effects of aging on anterior and posterior corneal astigmatism. Cornea. 2010;29:632-7.

17. Lee JH, Lee YW, Lee JS, Knorz MC, Auffarth GU, Choi CY. Comparison of color light-emitting diode corneal topographer and dual rotating Scheimpflug-placido topographer. J Ophthalmol. 2018:6764805. https://doi.org/10.1155/2018/6764805.

18. Klijn S, Reus NJ, Sicam VA. Evaluation of keratometry with a novel color-LED corneal topographer. J Refract Surg. 2015;31:249-56.

\section{Ready to submit your research? Choose BMC and benefit from:}

- fast, convenient online submission

- thorough peer review by experienced researchers in your field

- rapid publication on acceptance

- support for research data, including large and complex data types

- gold Open Access which fosters wider collaboration and increased citations

- maximum visibility for your research: over $100 \mathrm{M}$ website views per year

At $\mathrm{BMC}$, research is always in progress.

Learn more biomedcentral.com/submissions 